LIBRO

J. M. Coetzee, Elizabeth Costello: Ocho Lecciones

(Barcelona: Mondadori, 2004), 238 págs. Traducción de Javier Calvo.

\title{
EL DELIRIO DE J. M. COETZEE
}

\section{Gonzalo Contreras}

J. M. Coetzee es un escritor de ideas. La lucha interracial sudafricana es una de ellas, la defensa de la fauna es otra. Su obra da cuenta de la intensidad con que el sudafricano ha asumido sus banderas de lucha. El análisis de sus textos nos lleva a la vieja cuestión de la pertinencia de la ideología de un autor en su creación artística si ésta le agrega un valor, o bien, puede jugar en su contra.

\section{ـ . . Coetzee es delgado, vegetariano militante; sus escritos} contra el sacrificio y el consumo de animales son virulentos. Se sabe que es un hombre de humores cambiantes. La parquedad de su saludo con el rey de Suecia al momento de recibir el Premio Nobel es elocuente. Se dudó incluso que asistiera ya que es reacio a toda circunstancia social. Es como si el mundo le disgustara, pero no sería el primer escritor que sufre de ese síndrome. Es más bien habitual. ¿A dónde va todo esto? ¿Qué tiene que ver la personalidad con la obra de J. M. Coetzee? Aparentemente nada. Ya hay

Gonzalo Contreras. Escritor y ensayista. Autor de las novelas La Ciudad Anterior (1991), el Nadador (1995), El Gran Mal (Alfaguara, 1998) y La Ley Natural (Ed. Sudamericana, 2004), y de los cuentos Los Indicados (Ed. Sudamericana, 2000). Colaborador literario en varias publicaciones nacionales. 
rastros de su "dificulté de être" en su espléndido Juventud, donde narra sus vicisitudes al llegar a Londres desde su natal Sudáfrica y de las palizas de soledad que recibía del nuevo medio que lo acogía. En el fondo un reseñador no tendría por qué inmiscuirse en estos aspectos de un autor. Algo me dice que en este caso sí es pertinente. Del mismo modo que podemos tratar el "caso" Kafka, desde la perspectiva de su personalidad, algo semejante ocurre con J. M. Coetzee. De otro modo, ¿cómo explicarse un libro tan particular, por decirlo eufemísticamente, surgido de la pluma del Nobel (2003) avecindado en Australia? La pregunta está en si Elizabeth Costello: Eight Lessons (Londres: Secker \& Warburg, 2003), su última creación, es una obra original o simplemente una chifladura. En la contraportada Carlos Fuentes señala a Coetzee como: "no sólo un escritor para escritores; es el escritor de escritores”. Me pregunto por qué un escritor restringiría su campo de acción sólo a los escritores. En Elizabeth Costello, Coetzee se encarga de eso, de darnos lecciones. Su lector natural debe ser un avezado hombre de letras o bien un aprendiz de filósofo. No nos resulta ajena la nueva tendencia, que se impone por aquí y por allá, en la cual el motivo de la narración no es la historia, sino las motivaciones, los procesos y el minucioso pormenor de cómo y por qué nuestro escritor escogió aquel tema y sus métodos para llevarlo a cabo. En otras palabras, nos debe importar la hazaña literaria del creador, más que lo que la obra narra. Siguiendo con este discurrir, habríamos llegado al fin de la ficción, al punto de tope de la imaginación. Coetzee no está lejos de este nuevo paradigma. Tematizar vidas de escritores o métodos de escritura está de moda.

¿Por qué esa introspección al propio acto creativo? ¿Por qué esa falta de fe en que lo narrado posee una propia autonomía donde logramos conseguir ese pequeño triunfo que es la suspensión del juicio en nuestro lector y su inmersión en el mundo de lo desconocido? Coetzee, al parecer, ha dejado de creer en ese propósito esencial, lo mismo que un Vila Matas, un Javier Marías. ¿Es interesante la figura del escritor y su personal periplo creativo?

Sin duda que lo es bajo la forma del ensayo. Pienso en textos de Kafka acerca del tema, de Henry James, como El Arte de la Ficción, en las Seis Propuestas para el Próximo Milenio de Italo Calvino, donde el escritor intenta fundamentar una estética que llevará a cabo, o de David Lodge. Coetzee lo hace bajo el formato de la novela. Para ello crea un extraño alter ego. Elizabeth Costello, escritora australiana de cierto éxito, mujer de setenta años, que a lo largo del libro pontificará sobre cuánto tema ronda la cabeza del propio Coetzee. Estamos, en suma, hablando de un libro de ideas. La acción es mínima y la señora Costello, de acuerdo con su edad, no tiene 
mucho qué hacer con su vida personal, como no sea dictar conferencias en colleges y universidades. Las conferencias son las que habría dado el mismo Coetzee, pero no sabemos si el sudafricano fue tan confuso y manipulador. El libro se divide en ocho partes, cada una de ellas es una conferencia, o si no es así, se trata de un extenso diálogo de Elizabeth con algún incauto interlocutor. La señora Costello no da tregua. Nada hay trivial, doméstico o asimilable con nuestras simples existencias. El problema no es que la señora Costello sea una pedante erudita, cosa que, por mucho sacar ronchas, podría convertirla en personaje; no se constituye en tal ya que no vemos a la mujer de verdad, escritora o no escritora, sino a un cúmulo de ideas que Coetzee quiso poner por escrito. Es ahí donde el autor falla en aquello que James definía como "la simpatía en el tratamiento del tema", y vuelvo entonces a las primeras frases de este artículo. No es que Coetzee se nos haga pesado de sobrellevar, sino en la innecesaria contundencia de su ideario. El autor nos agobia con su repertorio de certidumbres; es en el espacio de la duda y de la interpretación al cual todo lector tiene el justo derecho donde Coetzee nos arrincona.

La primera Lección, que así se llama, lleva por nombre "Realismo”. La primera frase del libro, pese a su oscuridad, nos pone ya en la senda: "En primer lugar está el problema del arranque, es decir, de cómo ir desde donde estamos ahora, y ahora mismo no estamos en ningún parte, hasta la orilla opuesta. Sólo es cuestión de cruzar, de tender un puente. La gente soluciona problemas así todos los días”. Coetzee debe cruzar el puente, que es su objetivo declarado, pero veamos cómo lo hace. Elizabeth Costello está ya cansada de su vida itinerante de conferencista y quisiera deshacerse de los rutinarios halagos de los homenajes y de la crítica. Pero Coetzee no le da esa oportunidad a la vieja mujer. Tendrá muchas conferencias por delante y, en teoría, irritables conversaciones con gente a la que no desea oír. No, su agenda está sobrecargada. En compañía de su hijo, John, astrónomo de cuarenta años, Elizabeth asiste a la ceremonia de premiación que le otorga el Altona College. Su cáustica entrevistadora para la ocasión pregunta a la invitada: “¿Qué es el realismo?”. Elizabeth responde: “Hubo una época en que lo sabíamos. Antes creíamos que cuando decía 'En la mesa hay un vaso de agua', existía un mesa y un vaso de agua, y solamente teníamos que mirar el mundo-espejo del texto para verlos (...). Pero todo eso terminó. Parece que el mundo-espejo se ha roto de manera irreparable”. Esta respuesta se da en el contexto de la cita de un cuento de Kafka, Informe para una Academia, en que un simio vestido de smoking da una charla a sus espectadores humanos. Sería un trabajo arduo establecer la relación que hace Coetzee entre una cosa y otra La charla del simio del cuento de Kafka 
volverá más adelante con majadera insistencia, pero a estas alturas no sabemos con certeza hacia dónde van las municiones de Costello, como no sea la relatividad de las especies. Dice a propósito: “Si conocen el relato, recordarán que está escrito en forma de monólogo, del monólogo de un simio. De esa forma ni el orador ni el público pueden ser inspeccionados desde una perspectiva externa”. Más allá de lo extenso del discurso (éstos son solamente muy breves extractos), no entendí nada. Por momentos me ha llegado a inquietar la salud mental del señor Coetzee. Como dijimos antes, nuestro premio Nobel tiene una especial relación con el mundo animal y pareciera que sólo él vislumbra una capacidad de entendimiento humano con simios, focas o albatros. El asunto está en que Elizabeth no tiene siquiera un canario, pero sí una opinión muy formada y excéntrica del mundo animal. Por aquí y por allá Coetzee se nos colará con las más extravagantes y discutibles ideas respecto del ser humano y una suerte de contraparte, el paraíso salvaje, un mundo adánico y voluntaristamente ideal, que no logra trasmitir a su personaje salvo como no sea bajo la forma del discurso. Es su propio hijo durante el mismo ciclo de conferencias, quien la interroga: “¿Puedo preguntarte algo? ¿Por qué la historia de la literatura? ¿Y por qué es tan lúgubre la historia de la literatura? El realismo: en este siglo nadie quiere oír hablar de realismo”. Para su respuesta, vuelve al simio de Kafka. Pero veamos el siguiente diálogo. Replica ella: “¿Qué preferirías? ¿Un zoo sin cuidadores, en que los animales entraran en trance cada vez que dejaras de mirarlos? ¿Un zoo de ideas? ¿Una jaula de gorilas con la idea de un gorila dentro, una jaula de elefantes llenas de ideas de elefantes”. “Te estás yendo del tema, madre. Y no te pongas tan nerviosa. Estamos hablando de literatura, de las reivindicaciones del realismo contra las reivindicaciones del idealismo”. Joke Klein Kranenberg, en su artículo “Sobre el Realismo en Coetzee” (El Mercurio, 27 junio, 2004), hace no menos barrocas reflexiones sobre el realismo en contraposición al idealismo, afirmando que, para Coetzee, el realismo se bate en retirada. Para Coetzee, según Kranenberg, “existirían en éste (el realismo) dos concepciones divergentes que entrarán en una compleja dialéctica a lo largo del libro; la concepción clásica-griega del realismo como mímesis o encarnación, y la concepción medieval-cristiana, como representación e imitación. La primera tiene su origen en un mundo primitivo en que los hombres a través de su participación en los ritos religiosos entraban en contacto directo con los dioses; mientras que la segunda postula la existencia de dos mundos radicalmente separados, uno trascendental y otro visible, que se acercan en la medida que el mundo visible sea una representación fidedigna del mundo trascendental”. Kranenberg habla de "inseguridades epistemológicas”, de "quitadas de piso al 
realismo. Tanto Coetzee como Costello se encontrarían en la tensión de la segunda opción, pero que a la vez parece imposible, un problema sin solución. Sin solución para Coetzee-Costello, la que finalmente deja los podios y pierde el contacto con el 'mundo real' hasta quedar encerrada en un mundo entera y opresivamente literario". Tal dilema aparece sospechoso. Como si el escritor que se levanta de su escritorio bajara la cortina, y por otro lado, que es posible vivir un mundo "enteramente literario". Estos dos estados irreconciliablemente puros son un burdo distingo. Resulta del todo obvio que no hay literatura sin el componente de la realidad, o de la experiencia, si se quiere, y ésta sólo se puede obtener en el material que mana de la primera y que, como experiencia de índole humana, no veo por qué no pueda tener el carácter de trascendente.

Pero sigamos con nuestra atormentada y aburrida señora Costello. Su siguiente conferencia es "La novela en África”. Aquí viene un verdadero festín. Elizabeth se encuentra con un viejo colega, Emmanuel Egudu, escritor nigeriano con el que en los últimos años se ha topado en diversos congresos. Egudu ha encontrado una actividad más rentable, animación de charlas literarias en grandes trasatlánticos de lujo. Le pregunta a nuestra agobiada Elizabeth si no le interesaría dar las mismas conferencias que viene dando por años, sólo que ahora a bordo. Los honorarios son todavía mejores. Elizabeth se embarca pasando tal vez por alto que no hay más concentrado de realidad que un crucero de lujo con ancianos jubilados en shorts. El gran paquebote, el Northern Lights, hará un crucero desde Christchurch hasta Ciudad del Cabo. Elizabeth formará parte de la plantilla de educación. No hay transición ninguna entre sus atribuladas disquisiciones anteriores y esta exótica aventura del trasatlántico. Ésta sirve más bien como escenario para las reflexiones de Egudu acerca de la literatura africana. Debe ser sin duda una de las "conferencias" menos interesantes. No porque no nos interese dicha literatura, de la que sabemos muy poco, sino por el tono lastimero que Coetzee da a esa condición. "Nosotros, nosotros, nosotros — piensa Elizabeth—, nosotros los africanos. 'No es lo nuestro'”. Nunca le ha gustado la forma excluyente de la palabra "nosotros".

Egudu ha vivido de su africanidad de un modo semejante al de muchos otros su latinoamericanidad. Es decir como una forma de exclusión de la gran torta del Occidente cultivado. Él es un peregrino de su negritud, movimiento esencialista africano. Para explicar su presencia en el paquebote, Egudu argumenta con cinismo: "Muy simple, es que este tipo africano se está ganando la vida. En su país, estoy intentando explicar, no se puede ganar la vida”. Luego de afirmar que no puede hablar propiamente de una literatura nigeriana, de hecho casi no se imprimen libros, se da la paradoja 
de que se gana la vida hablando de ella. Sólo podemos otorgarle a Elizabeth el beneficio que está harta de la perorata del nigeriano, le cree poco y su exotismo la abruma. Pero Coetzee jugará a todo lo largo del libro con esta extraña tensión. Elizabeth puede ser crítica de su amigo, pero el propio autor le otorga al personaje más de treinta páginas de un interminable discurso que sólo puede importarle únicamente a él, quiero decir, al propio Coetzee. El lector irá viendo a lo largo del libro cómo todos los tópicos abordados son una suma de las preocupaciones del propio Coetzee, las ponga en boca de quien las ponga. Elizabeth puede estar irritada con la lata exposición de la fundamental oralidad de la novela africana que expone Egudu. "La novela africana, la verdadera novela africana, es una novela oral. En la página permanece inerte, solamente vive a medias. Pero se despierta cuando la voz, procedente de las profundidades del cuerpo, insufla vida a las palabras y las pronuncia con voz alta. La novela africana es por tanto, afirmaría yo, en su mismo ser, y antes que se escriba la primera palabra, una crítica de la novela occidental”. Y así, suma y sigue. Hay que tener en cuenta que el discurso de Egudu es una conferencia y de ahí su tono doctrinal, pero las ocho partes del libro son ocho conferencias, así es que el lector tendrá que ir acostumbrándose a una larga prédica intelectual que requerirá de un buen cúmulo de fuerzas, y de paciencia. Vuelvo a mi interrogante anterior, si la conferencia no interesó en nada a nuestra protagonista, y menos a los aburridos pasajeros, ¿para qué darse el gasto?, ¿para qué crear este personaje de vendedor viajero de africanidades? La respuesta está sólo en Coetzee y en sus ensoberbecidas obsesiones.

Pero es con el tema de los animales donde Coetzee pierde toda medida. Elizabeth está acodada en la barandilla de borda. Los pasajeros observan la fauna del mar austral: "Pingüinos — dice el hombre que está junto a ella-. Pingüinos rey. Han venido a saludarnos. No saben qué somos”. Otra: "Un albatros — le comenta a la mujer en voz baja-. Así los llamamos en inglés. No sé cómo se llaman a sí mismos”.

El capítulo tres ahonda aún más en esta equiparación que hace el autor entre todas las especies animales, entre las que está el hombre, el peor de todos, por supuesto. El capítulo se llama “Los filósofos y los animales”. Veamos por qué. Elizabeth está invitada a dar una conferencia en el Appleton College, en alguna ciudad australiana, donde además vive su hijo John con su mujer. John está lleno de aprensiones respecto de qué dirá su madre en los tres días de conferencias. No confía del todo en su salud mental y sabe que Elizabeth es verbalmente incontinente. Pero, más bien, no confía en la radicalidad de sus ideas. Elizabeth, como su creador, o alter ego, es estrictamente vegetariana. Al momento de la cena, a horas de su llegada, 
Mrs. Costello repara que no están sus dos nietos. "Mamá —responde él一, es que los niños van a cenar pollo”. Razón suficiente. Con Norma, su nuera, nunca se han llevado bien. Ésta nunca ha dejado de decirle a su marido que encuentra que los libros de su suegra están sobrevalorados, y que sus opiniones sobre los animales, los derechos y las relaciones éticas con los animales son bobas y sentimentales. Una vez más Coetzee usa una contraparte para refutar sus propias ideas y darles un viso controversial y de subjetividad. Pero no pasa de eso. Su primera conferencia versará sobre el relato de Kafka, Informe para una Academia, "que trata de un simio cultivado, Pedro el Rojo, que está ante los miembros de una sociedad cultural contando la historia de su vida, de su ascenso de bestia a algo cercano al hombre”. "Al hablarles hoy de los animales — continúa Elizabeth— les haré el favor de evitar el recital de horrores que son sus vidas y sus muertes. Aunque no tengo razones para creer que tengan presente lo que se les hace hoy día a los animales en los centros de producción (ya no me atrevo a llamarlos granjas), en los mataderos, en los centros pesqueros y en los laboratorios del mundo entero". Así comienza Elizabeth. John quiere morirse y, en alguna medida, el lector también. Las ideas son tan elementales como lo ha señalado Norma. Un amigo, intelectual chileno, me dice que todo no es más que un chiste, un guiño al lector. Me cuesta creerlo. En innumerables entrevistas Coetzee ha expresado ideas muy semejantes y su tema es conocidamente ése. Poco nos importa si John y Norma creen que la anciana efectivamente está haciendo el loco. Al autor, en todo caso, esto no parece importarle. En este descabellado capítulo Coetzee nos expondrá en voz de Elizabeth Costello su ideario ambientalista.

Desde luego hace una comparación muy discutible entre los crímenes de Hitler y los campos de concentración. Su línea argumental es que si bien la población civil podía sospechar de esas atrocidades, no hizo nada por evitarlas y guardó un silencio culpable, enmudeció sus conciencias. Son, en buenas palabras, todos los alemanes cómplices. "Perdieron la humanidad, a nuestros ojos, porque hicieron gala de cierta ignorancia voluntaria. Digamos que en Alemania se cruzó cierta línea que llevó a la gente más allá de las condiciones normales de crueldad”. El gran crimen del Tercer Reich es haber tratado a la gente como animales. Un comedor de carne es, para Elizabeth Costello-Coetzee, tan abominable como un colaborador del régimen nazi. Sigamos con ella: "Esta mañana me han llevado a dar una vuelta en coche por Walthman. Parece un pueblo agradable. No vi ninguna granja industrial, y ningún matadero. Y sin embargo estoy segura que están aquí. Han de estarlo”. A esas alturas el espectador de la conferencia como el lector se preguntarán legítimamente de qué diablos me están hablando. 
"Y para ser puntillosa, afirmar que no hay comparación, afirmar que Treblinka era, por decirlo así, una empresa metafísica dedicada exclusivamente a la muerte y a la aniquilación, mientras que la industria cárnica está dedicada en última instancia a la vida (una vez que sus víctimas han muerto, al fin y al cabo no se las convierte en ceniza ni se las entierra, sino al contrario, se las corta, se las refrigera y se las empaqueta para que puedan ser consumidas en la comodidad de vuestros hogares), serviría de tan poco consuelo a sus víctimas como habría servido (y perdón por el mal gusto de lo que sigue) pedir a las víctimas de Treblinka que perdonaran a sus asesinos porque necesitaban su grasa corporal para hacer jabón y su pelo para rellenar colchones”. Ésa es una de las declaraciones de nuestra escritora, que, como verá el lector, no tiene ningún empacho en ocultar su fundamentalismo o absolver o comprender al asesino que se come una hamburguesa. Lo que ocurre, y éste es el asunto central, es que Coetzee establece la hipótesis acerca de la naturaleza del alma de los animales y que refuta la tesis de “Santo Tomás, según el cual como sólo el hombre está hecho a imagen de Dios, y participa del ser de Dios, no importa cómo tratemos a los animales”. Fustiga a Kant por no haberse preocupado del tema y pone en duda su teoría de que "la razón no constituye el ser del universo, ni el ser de Dios. $\mathrm{Al}$ contrario, creo que la razón sólo viene a constituir el ser del pensamiento humano”. En el fondo Coetzee postula una visión antropomórfica del mundo, en su segunda acepción, en la que el hombre y las cosas, incluidos los animales, tienen y provienen de una misma naturaleza. No es un gran hallazgo en la medida que es tal cual. Lo que lleva a sospecha en el discurso de nuestro autor es su profunda desconfianza de la naturaleza humana. 